\section{Aspirin take two}

Aspirin: the story of a wonder drug

Diarmuid Jeffreys

London: Bloomsbury Publishing; 2004

335 pp. \$27.95 (paper) ISBN 074757443

$\mathrm{I}$ once met a man whose child had inadvertently entertained the parish priest by asking him to provide more details to the story of "Gladly the crosseyed bear." Similarly, I recall as a child being confused by television commercials that extolled the virtues of a medication with a "bear cross on every tablet." The medication in question was Aspirin of course, its trademark the famous "Bayer cross," one company's ultimately successful attempt to brand its product in a world where fierce competition for market share among arguable equals continues to complicate, confuse and threaten.

In Aspirin: the Story of a Wonder Drug, a new book by British journalist and television producer Diarmuid Jeffreys, the discovery of acetylsalicylic acid, or ASA, and its subsequent branding is wonderfully laid out. Unlike the rather dry, chalky medication whose history it traces, this account is highly palatable; Jeffreys introduces an eclectic menu of characters (some less savoury than others) and clearly traces the complex story of how ASA became "one of those rare commodities whose very existence seems to have influenced history, its invention provoking decisions and events that might not have otherwise occurred."

Jeffreys outlines in great detail the connection between Farbenfabriken Bayer, a company ultimately descended from a mid-nineteenth century partnership between dye merchants Friedrich Bayer and Johann Weskott, and the subsequently notorious Interessengemeinschaft der Deutschen Teefarbenfabriken (Community of Interests of the German Tar-dye Factories), or IG Farben. He pulls no punches when he states that the cartel that was IG Farben was "one of the buttresses of the most grotesque and brutal dictatorship [sic] the world has ever seen," that of Hitler's Third Reich. "The line from Aspirin," Jeffreys writes, "leads all the way on up to Auschwitz."
Another highly interesting and thought-provoking theme is the popularization of ASA around the globe and the numerous fortunes that were made and lost along the way. Various and sundry legal machinations, patent contests and under-the-table shenanigans are related in simple prose that is not, for all that, bereft of colour. Jeffreys writes well and provides a useful index as well as an extensive bibliography. Moreover, he manages to provide sufficient scientific and legal detail to adequately inform but not intimidate a general readership. Although one could quibble with his perhaps careless use of the expression "heart failure" in one or two places, this is of less significance than the fact that he provides accurate information (within limits) regarding ASA's use as an antiplatelet agent and the benefits that seem to accrue to regular users. Notions of primary versus secondary prevention are not addressed, although Jeffreys reminds

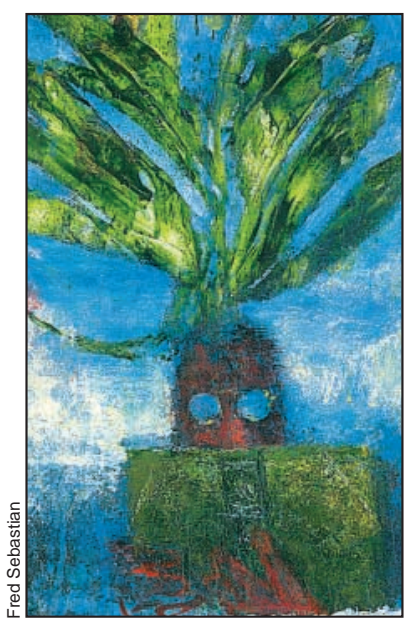
his readers that "Aspirin is not a cureall ... [and that] it is worth repeating that it can have side effects."

Duly and interestingly noted is the fact that, in spite of a growing number of small studies reporting the efficacy of ASA in fighting a broad range of cancers, not to mention AIDS, simple economics precludes the likelihood of any large-scale research. As Jeffreys notes:

[A]spirin is eighty or more years out of patent. It is also extremely inexpensive ... . Its producers will always fund a few trials out of altruism but there's no real financial incentive for them to do more because the profit margins on the product are so small and anyone can make it.

PGY1
Jeffreys gives relatively short shrift to the late twentieth-century coalescing of numerous pharmaceutical companies into the multinational giants that dominate the industry today. Also lacking - for obvious reasons - in the brief segments devoted to selective COX-2 inhibitors, are references to the ongoing "revelations" prominent in the news today. Nevertheless, these are minor criticisms; the book is less an esposé of the pharmaceutical and medical industries than a history of a medication that in today's regulated climate might not have made it to market.

Physicians and laypersons alike need always and everywhere to be wary of "wonder drugs." This especially is true in these post-Vioxx days, when arguably well-informed patients are more and more skeptical of the benefits promised by the various medications they are prescribed so frequently. Indeed, it appears that patients are not only skeptical about the putative returns of taking their medications; they are increasingly and justifiably suspicious of the physicians who prescribe them.

In spite and perhaps because of this, Jeffreys' history of Aspirin well repays the easy hours required to read it. In these halcyon days of "evidence-based medicine," we do well to remember that the jury is always out. The simple passage of time dictates that tomorrow inevitably will bring new evidence (or at least bring new evidence to light). And perhaps we ought all to keep in mind the words of an eighteenth-century satirist quoted thusly by Jeffreys: "Cur'd yesterday of my disease, I died last night of my Physician."

\section{Ted St. Godard}

Family Medical Centre

University of Manitoba

Winnipeg, Man. 